\title{
Effect of Personalized Dialysate Sodium Prescription on Plasma Sodium Concentration and Sodium Set Point in Conventional, Quotidian and Nocturnal Home Hemodialysis
}

Benjamin Thomson ${ }^{1,2^{*}}$, Lihua $\mathrm{Li}^{3}$ and Robert Lindsay ${ }^{2,3,4}$

${ }^{1}$ Division of Nephrology, Kingston General Hospital, Kingston, Ontario, Canada

${ }^{2}$ Department of Medical Biophysics, Western University, London, Ontario, Canada

${ }^{3}$ Kidney Clinical Research Unit, London Health Sciences Centre and Western University, London, Ontario, Canada

${ }^{4}$ Division of Nephrology, Department of Medicine, London Health Sciences Centre and Western University, London, Ontario, Canada

*Corresponding author: Benjamin Thomson, 76 Stuart Street, Burr 3-38, Queen's University, Kingston Ontario K7L-2V7, Canada, Tel: (613) 549-6666 X7306; E-mail: thomsonb@kgh.kari.net

Received Date: June 14, 2017; Accepted Date: June 19, 2017; Published Date: June 26, 2017

Copyright: (C) 2017 Thomson B, et al. This is an open-access article distributed under the terms of the Creative Commons Attribution License, which permits unrestricted use, distribution, and reproduction in any medium, provided the original author and source are credited.

\begin{abstract}
Introduction and objectives: In thrice weekly conventional hemodialysis, dialysate sodium prescription can cause intradialytic plasma sodium shifts, and undesirable symptoms. However, changes in pre-dialysis plasma sodium setpoint are not observed. Whether these clinical observations are observed in quotidian or nocturnal home hemodialysis has not been prospectively evaluated.
\end{abstract}

Methods: A randomized crossover study of conventional, quotidian and nocturnal home hemodialysis patients was performed. Dialysate sodium was personalized $3 \mathrm{mmol} / \mathrm{L}$ above (HIGHDIALSOD) or below (LOWDialSOD) the $\mathrm{SP}$, with 100 days for each crossover studies period.

Results: Plasma $\mathrm{Na}^{+}$decreased during hemodialysis in LOWDialSOD study period (136.8 to $135.0 \mathrm{mmol} / \mathrm{L}$, $\mathrm{p}=0.002)$. Pre- $\mathrm{Na}^{+} \mathrm{SP}(137.4$ to $136.8 \mathrm{mmol} / \mathrm{L}, \mathrm{p}=0.03)$ and Pre- $\mathrm{Na}^{+} \mathrm{SP}$ slope $(0.014$ to $-0.015 \mathrm{mmol} / \mathrm{L} / \mathrm{day}$, $p=0.009$ ) decreased from HIGHDialSOD to LOWDialSOD study periods.

Conclusions: Personalization of Dial- $\mathrm{Na}^{+}$to below SP leads to reductions in plasma sodium concentration during hemodialysis, in conventional, quotidian and nocturnal home hemodialysis patients. Furthermore, sodium set point changes in response to Dial- $\mathrm{Na}^{+}$prescription. This has the potential to lead to adverse outcomes in a patient population that is followed less frequently and stringently than the in-center hemodialysis population.

Keywords: Sodium set point; Dialysate sodium; Quotidian hemodialysis; Nocturnal hemodialysis; Plasma sodium

\section{Introduction}

Cardiovascular disease is the leading cause of mortality in hemodialysis patients $[1,2]$. Chronic volume and pressure overload are major contributing factors, leading to hypertension, left ventricular hypertrophy and death [3-6]. Several strategies to improve these risk factors have demonstrated success, including dietary sodium restriction $[7,8]$, increasing hemodialysis frequency and duration, [9-14] and volume management guided by bioimpedance $[15,16]$. Of recent relevant interest to this topic is the dialysate sodium prescription [17-19].

Pre-dialysis plasma sodium concentration is relatively stable in thrice weekly conventional hemodialysis patients, and is thus termed the "sodium setpoint" (SP) [20-22]. When dialysate sodium concentration is less than SP, increased diffusive sodium removal occurs, leading to improvement in interdialytic weight gain, pre- and post-dialysis blood pressure $[17,19,23-25]$ and perhaps also in cardiovascular outcomes and mortality [26,27]. However, marked reduction in dialysate sodium concentration gives rise to intradialytic symptoms including intradialytic hypotension $[28,29]$. This may be mediated by intradialytic shifts in plasma sodium concentration [28].

While effects of personalized dialysate sodium prescription are well described in conventional thrice weekly hemodialysis patients, these outcomes have not been prospectively evaluated in quotidian or nocturnal home hemodialysis patients. Whether plasma sodium concentration changes during more frequent or longer hemodialysis sessions is unknown, and whether such changes impact the sodium set point has not been prospectively evaluated. Since these patients often dialyze at home, where their clinical follow-up is less frequent, it is essential to determine if set point changes over time. Three objectives were tested in a randomized crossover study, in conventional, quotidian and nocturnal home hemodialysis patients. Our first objective was to determine if personalized dialysate sodium prescription modified plasma sodium concentration from the start to the end of a hemodialysis session. Our second objective was to determine if a change in dialysate sodium concentration altered the pre-dialysis sodium set point. Our third objective was to determine if dialysis frequency or duration modulated changes in either plasma sodium throughout dialysis or sodium set point. 


\section{Methods}

\section{Study population}

All patients in the home hemodialysis program of the Southwestern Ontario Regional Renal Program were considered. Patients were excluded if they were under the age of 18 , pregnant, or not expected to survive 6 months.

\section{Study design}

A randomized crossover trial design was used. The average of the two most recent monthly pre-dialysis plasma sodium (Pre- $\mathrm{Na}^{+}$) measurements defined the patient's sodium setpoint (SP). Patients were randomized to a dialysate sodium (Dial- $\mathrm{Na}^{+}$) concentration group either $3 \mathrm{mmol} / \mathrm{L}$ above $\left(\right.$ DialNa $^{+}=\mathrm{SP}^{+3}=$ HIGHDialSOD) or 3 $\mathrm{mmol} / \mathrm{L}$ below $\left(\mathrm{DialNa}^{+}=\mathrm{SP}^{-3}=\mathrm{LOWDialSOD}\right)$ their SP (Figure 1). Dialysate sodium concentration range was restricted to between 130 and $150 \mathrm{mmol} / \mathrm{L}$, because of concerns of clinical effects. After 100 days, patients crossed over study periods. Patients were followed for another 100 day period and then the study was completed.

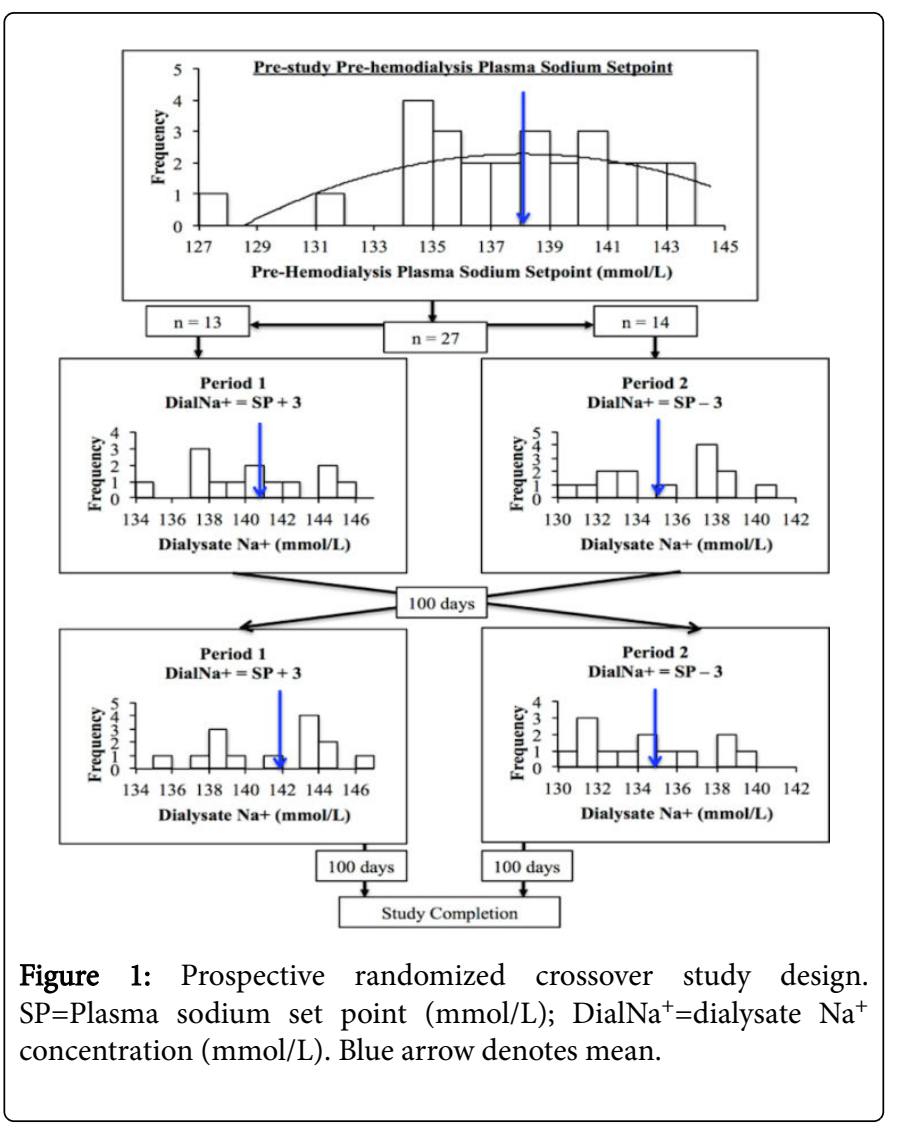

\section{Blood sample collection}

Pre-dialysis and post-dialysis blood samples were collected biweekly from the arterial blood line, using a standard slow blood and stop dialysate method. Locking solution ( $2 \mathrm{~mL}$ of $4 \%$ citrate) and a small amount of blood ( $\sim 2$ to $5 \mathrm{~mL}$ ) are spent prior to blood collection. The samples are centrifuged and refrigerated until delivered to the laboratory, within 12 hours of collection. Of interest in this study were pre-dialysis $\left(\right.$ Pre- $\left.\mathrm{Na}^{+}\right)$and post-dialysis $\left(\mathrm{Post}_{-} \mathrm{Na}^{+}\right.$) plasma $\mathrm{Na}^{+}$. Only outpatient blood tests were considered, to eliminate the confounding effect of acute illness.

\section{$\mathrm{Na}^{+}$concentration measurement}

Plasma $\mathrm{Na}^{+}$concentration were measured using Roche Modular $\mathrm{P}$ Chemistry Analyzer (Roche Diagnostics, Laval, Quebec, Canada) with indirect ion selective electrodes. Dialysate $\mathrm{Na}^{+}$concentration was determined using online conductivity measurements in the Fresenius $\mathrm{H}$ series hemodialysis machine. Dialysate conductivity is strongly correlated to dialysate sodium concentration $\left(\mathrm{r}^{2}=0.997\right.$; Dialysate $\mathrm{Na}$ ${ }^{+}=9.46 \times$ Dialysate Conductivity +6.5$)$, as previously described [30].

\section{Database creation}

Demographic, clinical and hemodialysis data were collected from the electronic patient record (Power Chart by Cerner), home hemodialysis run sheets and the outpatient hemodialysis unit paper chart. Background factors of interest included patient age, sex, diabetes status, height $(\mathrm{cm})$, weight $(\mathrm{kg})$, residual renal function $(\mathrm{mL} / \mathrm{min} \times$ $1.73 \mathrm{~m}^{2}$ ) and vintage of hemodialysis (days). Residual renal function was calculated as previously described [31]. Hemodialysis records were used to record dialysis frequency (sessions per week) and duration (hours per session) throughout the study.

Dialysate to pre-dialysis plasma sodium gradient $\left(\mathrm{DPNa}^{+}\right)$and postdialysis $\left(\right.$ Post- $\left.\mathrm{Na}^{+}\right)$to pre-dialysis $\left(\mathrm{Pre}-\mathrm{Na}^{+}\right)$plasma sodium gradient $\left(\mathrm{PPNa}^{+}\right)$concentration were also recorded. We decided a priori that a minimum of 3 observations per $\mathrm{DPNa}^{+}$and $\mathrm{PPNa}^{+}$would be required in each of HIGHDialSOD and LOWDialSOD study periods for a patient to be included in the final analysis.

\section{Ethics}

Ethics approval was granted by the Western University Health Sciences Research Ethics Board. Informed written consent was obtained from all patients. The study was conducted in accordance with the 1964 Helsinki Declaration.

\section{Statistics}

Data were analyzed using the Statistical Package for Social Sciences version 19.0. The mean, median, standard error and interquartile range were calculated for all background demographic and clinical factors.

\section{Statistics- objective 1}

The average pre- and post-dialysis plasma sodium concentrations were calculated for each patient for each study period. The group average pre- and post-dialysis plasma sodium concentrations were then compared between HIGHDialSOD and LOWDialSOD, using paired two-tailed student $t$-tests with a value of 0.05 considered for statistical significance.

\section{Statistics- objective 2}

A change in SP was defined in two ways (Figure 2). Firstly, the average Pre- $\mathrm{Na}^{+}$differed between HIGHDialSOD and LOWDialSOD study periods. Secondly, the slope of Pre- $\mathrm{Na}^{+}$over time differed between study periods. Differences were detected using paired twotailed student $\mathrm{t}$-tests with a value of 0.05 considered for statistical significance. 
Citation: Thomson B, Li L, Lindsay R (2017) Effect of Personalized Dialysate Sodium Prescription on Plasma Sodium Concentration and Sodium Set Point in Conventional, Quotidian and Nocturnal Home Hemodialysis. J Nephrol Ther 7: 294. doi:10.4172/2161-0959.1000294

Page 3 of 6

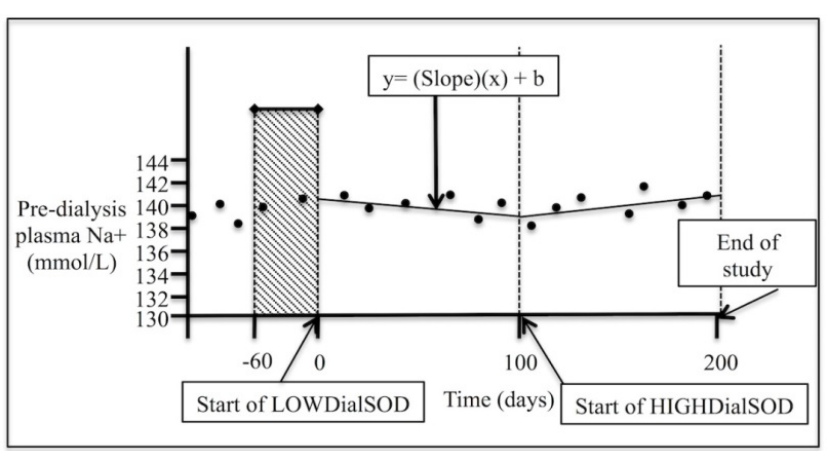

Figure 2: Endpoints to determine change in pre-dialysis plasma $\mathrm{Na}^{+}$ set point.

\section{Statistics- objective 3}

Pearson correlation coefficients were calculated to determine if changes in SP were modulated by hemodialysis frequency or duration. $\mathrm{Y}$ axis included either change in pre- $\mathrm{Na}^{+}$or slope of Pre- $\mathrm{Na}^{+}$from HIGHDialSOD to LOWDialSOD study periods. $\mathrm{X}$ axis included hemodialysis frequency or duration. Slope of correlation was calculated and two-tailed $\mathrm{p}$ values were determined with a value of 0.05 for statistical significance.

\section{Results}

There were 43 patients screened for this study (Figure 1), 16 of whom were excluded for reasons that included pregnancy $(n=1)$, age less than $18(n=1)$, life expectancy less than 6 months $(n=3)$ or declining participation $(\mathrm{n}=11)$. A total of 27 patients started and completed both study periods. No patient had fewer than $3 \mathrm{DPNa}^{+}$or $\mathrm{PPNa}^{+}$measurements in either study period; thus, all patients were included in data analysis. The mean difference between the two averaged monthly Pre- $\mathrm{Na}^{+}$samples, at the beginning of the study, was $0.92 \mathrm{mmol} / \mathrm{L}$, with the majority of differences $(23 / 26)$ being less than or equal to $2 \mathrm{mmol} / \mathrm{L}$.

Mean and median SP was 138.1 and $138.5 \mathrm{mmol} / \mathrm{L}$, with an interquartile range of 135.5 to $141.0 \mathrm{mmol} / \mathrm{L}$ (Figure 1 and Table 1). The study population was an average age of 54.2 years, with $40.7 \%$ female and $33.3 \%$ diabetic (Table 1). Dialysis frequency averaged 4.4 sessions per week, with a median of 4.0 weekly sessions. Dialysis duration averaged 4.8 hours per session, with a median of 4.0 hours. More than half of patients had no residual renal function, with a mean of 0.51 and median $0.00 \mathrm{~mL} / \mathrm{min}$.

\begin{tabular}{|c|c|c|c|c|}
\hline & Mean & Median & $\begin{array}{l}\text { Standard } \\
\text { Deviation }\end{array}$ & Interquartile Range \\
\hline Number Patients & 27 & & & \\
\hline Pre-dialysis plasma sodium set point (mmol/L) & 138.1 & 138.5 & 3.8 & $135.5-141.0$ \\
\hline Age (years) & 54.2 & 54.9 & 11.6 & $48-62$ \\
\hline Sex (\% female) & 40.7 & & & \\
\hline Diabetes (\%) & 33.3 & & & \\
\hline Weight (kg) & 82.9 & 83.1 & 22.7 & $69-92$ \\
\hline Height (cm) & 169.9 & 172.0 & 12.4 & $165-176$ \\
\hline Body mass index $\left(\mathrm{kg} / \mathrm{m}^{2}\right)$ & 28.6 & 27.7 & 6.6 & $25-32$ \\
\hline Dialysis Frequency (sessions per week) & 4.4 & 4.0 & 1.3 & $3-6$ \\
\hline Dialysis Duration (hours per session) & 4.8 & 4.0 & 2.1 & $3-7$ \\
\hline Vintage (days) & 2539 & 1654 & 2720 & $745-3159$ \\
\hline Residual renal function (mL/min) & 0.51 & 0.00 & 1.25 & $0.00-0.00$ \\
\hline Systolic BP (mm Hg) & 136.6 & 131.0 & 23.8 & $121-148$ \\
\hline Diastolic BP (mm Hg) & 75.6 & 73.0 & 12.2 & $68-84$ \\
\hline Hemoglobin $(\mathrm{g} / \mathrm{dL})$ & 113.2 & 111.0 & 15.6 & $106-121$ \\
\hline Albumin $(\mathrm{g} / \mathrm{L})$ & 40.8 & 41.0 & 3.4 & $40-42$ \\
\hline
\end{tabular}

Table 1: Background demographic and clinical data.

\section{Objective 1}

Pre-Na+ and Post- $\mathrm{Na}^{+}$did not differ in HIGHDialSOD study period (137.4 to $137.8 \mathrm{mmol} / \mathrm{L}, \mathrm{p}=0.45$ ). However, plasma $\mathrm{Na}^{+}$fell throughout dialysis (136.8 to $135.0 \mathrm{mmol} / \mathrm{L}, \quad \mathrm{p}=0.002)$ in LOWDialSOD study period (Figure 3 ). 
Page 4 of 6

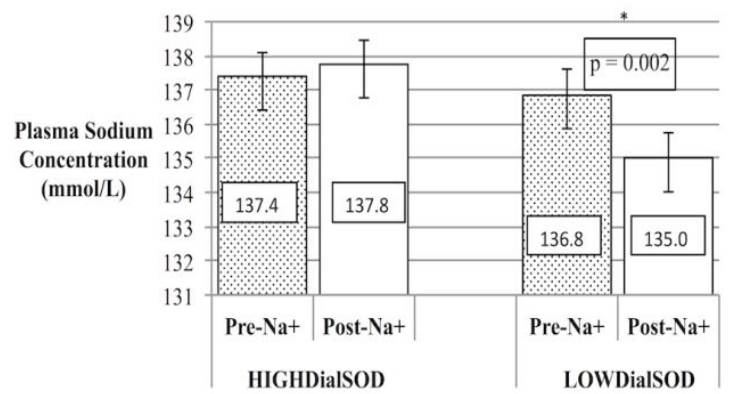

Figure 3: Pre- and post- dialysis plasma sodium concentration with high (period 1) or low (period 2) personalized dialysate sodium. HIGHDialSOD $=$ Study period in which Dialysate Sodium concentration $3 \mathrm{mmol} / \mathrm{L}$ greater than set point; LOWDialSOD = Study period in which Dialysate Sodium concentration $3 \mathrm{mmol} / \mathrm{L}$ lower than set point; Post- $\mathrm{Na}^{+}=$Post-dialysis plasma sodium concentration; Pre- $\mathrm{Na}^{+}=$Pre-dialysis plasma sodium concentration.

\section{Objective 2}

Pre- $\mathrm{Na}^{+}$sodium setpoint decreased from HIGHDialSOD to LOWDialSOD study period (137.4 to $136.8 \mathrm{mmol} / \mathrm{L}, \mathrm{p}=0.03$ ) (Table 2 ).
The slope of Pre- $\mathrm{Na}^{+}$also decreased from HIGHDialSOD to LOWDialSOD study periods ( 0.014 to $-0.015 \mathrm{mmol} / \mathrm{L} / \mathrm{day}, \mathrm{p}=0.009$ ).

\begin{tabular}{|c|c|c|c|}
\hline \multirow[b]{2}{*}{ Outcome } & \multicolumn{3}{|c|}{ Study Period } \\
\hline & $\begin{array}{l}\text { HIGHDialS } \\
\text { OD }\end{array}$ & $\begin{array}{l}\text { LOWDialS } \\
\text { OD }\end{array}$ & $\mathbf{p}$ \\
\hline Pre-dialysis plasma sodium (mmol/L) & 137.4 & 136.8 & 0.03 \\
\hline $\begin{array}{l}\text { Slope of pre-dialysis plasma sodium } \\
{[(\mathrm{mmol} / \mathrm{L}) / \text { day }]}\end{array}$ & 0.014 & -0.015 & $\begin{array}{l}0.00 \\
9\end{array}$ \\
\hline \multicolumn{4}{|c|}{$\begin{array}{l}\text { HIGHDialSOD = Dialysate sodium concentration } 3 \mathrm{mmol} / \mathrm{L} \text { higher than pre- } \\
\text { dialysis sodium set point; LOWDialSOD = Dialysate sodium concentration } 3 \\
\mathrm{mmol} / \mathrm{L} \text { lower than pre-dialysis sodium set point }\end{array}$} \\
\hline \multicolumn{4}{|l|}{ Bolded text signifies statistically significant findings } \\
\hline
\end{tabular}

Table 2: Difference in absolute and slope of pre-dialysis plasma sodium set point with two personalized dialysate sodium concentrations.

\section{Objective 3}

The change in Pre- $\mathrm{Na}^{+}$across study periods was not correlated to hemodialysis frequency $(\mathrm{R}=0.264, \mathrm{p}=0.193)$ or duration $(\mathrm{R}=0.032$, $\mathrm{p}=0.877$ ) (Table 3). Likewise, the change in slope of Pre- $\mathrm{Na}^{+}$across study periods was not correlated to hemodialysis frequency $(\mathrm{R}=0.172$, $\mathrm{p}=0.401)$ or duration $(\mathrm{R}=0.067, \mathrm{p}=0.745)$.

\begin{tabular}{|l|l|l|l|l|l|l|}
\hline & \multicolumn{2}{|l|}{ Dialysis Frequency } & \multicolumn{2}{l|}{ Dialysis Duration } \\
\hline Outcome & $\mathbf{R}$ & Slope & P & R & Slope & P \\
\hline Pre-dialysis plasma sodium (Pre-Na $\left.{ }^{+}\right)(\mathrm{mmol} / \mathrm{L})$ & 0.264 & 0.464 & 0.193 & 0.032 & 0.036 & 0.877 \\
\hline Slope pre-dialysis plasma sodium (mmol/L/day) & 0.172 & 0.007 & 0.401 & 0.067 & 0.002 & 0.745 \\
\hline P=p-value; R=Pearson's correlation coefficient & \multicolumn{5}{|l}{} \\
\hline
\end{tabular}

Table 3: Effect of hemodialysis frequency and duration on change across study periods in absolute and slope of pre-dialysis sodium set point.

\section{Discussion}

Reduction in dialysate sodium concentration can reduce IDWG, blood pressure and cardiovascular outcomes [17,19,24]. However, it may also give rise to intradialytic hypotension $[28,29]$. mediated by intradialytic shifts in plasma sodium concentration [28]. Whether personalized dialysate sodium prescription associates with intradialytic shifts in plasma sodium in quotidian or nocturnal home hemodialysis patients is previously unreported.

This randomized crossover study included patients with a spectrum of dialysis frequency (mean $=4.4$, interquartile range $=3$ to 6 sessions per week) and duration (mean=4.8, interquartile range 3-7 hours) (Table 1). There was a high number of females $(40.7 \%)$ and diabetics $(33.3 \%)$ and a wide spectrum of other demographic and clinical factors such as blood pressure, age and body habitus. Every patient had at least 3 recordings of $\mathrm{PPNa}^{+}$and $\mathrm{DPNa}^{+}$during each study period. The sodium set point (SP) varied widely in our study population (interquartile range 135.5 to 141.0, Table 1 and Figure 1). Thus, our study population was representative of a typical hemodialysis population, and outcomes were evaluated with rigor.
While the HIGHDialSOD plasma sodium did not change over dialysis (137.4 to $137.8 \mathrm{mmol} / \mathrm{L}, \mathrm{p}=0.45)$, there was a significant decrease from Pre- $\mathrm{Na}^{+}$to Post- $\mathrm{Na}^{+}$in the LOWDialSOD study period (136.8 to $135.0 \mathrm{mmol} / \mathrm{L}, \mathrm{p}=0.002$ ) (Figure 3). This is consistent with Suckling et al. recent work [28]. While the magnitude of intradialytic plasma sodium change was small in our study, there is still reason for concern. Firstly, intradialytic decrease in plasma sodium is linked to intradialytic hypotension [28], which independently increases risk of death [29]. Secondly, ignoring patient-specific SP by facility level decreases in dialysate sodium concentrations will lead to significantly negative $\mathrm{DPNa}^{+}$gradients in some patients. Again, this increases the risk of intradialytic hypotension. Ultimately, selection of dialysate sodium should be personalized to the patient to limit adverse outcomes of a very positive $\mathrm{DPNa}^{+}$, while simultaneously avoiding the complications of intradialytic plasma sodium shifts from a negative $\mathrm{DPNa}^{+}$; this can only be done by regularly following the Pre- $\mathrm{Na}^{+}$and adjusting the Dial- $\mathrm{Na}^{+}$accordingly.

Net diffusive intradialytic ionic sodium flux reflects several competing mechanisms. Sodium concentration in serum water ranges from 6 to $9 \mathrm{mmol} / \mathrm{L}$ higher than in whole serum. This is because plasma water constitutes about $93 \%$ of total plasma, whereas it is $100 \%$ 
Page 5 of 6

of total dialysate volume [32]. However, this difference is compensated by the Gibbs-Donnan effect, in which anionic plasma proteins are not diffusible through the dialysis membrane, and therefore create an electric field attracting sodium, reducing diffusible sodium by 4 to $5 \%$ [33]. Sodium ions complex with anions in both serum water and dialysate, further reducing diffusible sodium in both compartments [34]. These forces cause the actual plasma sodium concentration to be higher than measured; when $\mathrm{DNa}^{+}$is greater than $\mathrm{PNa}^{+}$, a neutral ionic mass balance persists so long as $\mathrm{DPNa}^{+}$is not greater than 5 $\mathrm{mmol} / \mathrm{L}$ [35]. Thus, when $\mathrm{DNa}^{+}$is personalized to be lower than measured $\mathrm{PNa}^{+}$, the actual $\mathrm{DPNa}^{+}$will be less than measured. This explains why there was either an intradialytic plasma sodium or SP change in the HIGHDialSOD period, when a $\mathrm{DNa}^{+}$was chosen to be only $3 \mathrm{mmol} / \mathrm{L}$ higher than $\mathrm{PNa}^{+}$. On the other hand, an intradialytic plasma sodium and SP change were observed in the LOWDialSOD period, since the personalized $\mathrm{DNa}^{+}$(of $3 \mathrm{mmol} / \mathrm{L}$ lower than $\mathrm{PNa}^{+}$) led to a $\mathrm{DPNa}^{+}$that was even lower than $-3 \mathrm{mmol} / \mathrm{L}$, since actual $\mathrm{PNa}^{+}$ was greater than measured.

There are other potential mechanisms for the observation that SP changed in LOWDialSOD but not HIGHDialSOD period. Firstly, serum albumin concentration didn't change between both study periods; thus, maintenance of trans-dialysis membrane electrical potential during the LOWDialSOD period required increased movement of cationic serum sodium out of the blood into the dialysate. On the other hand, during the HIGHDialSOD period, maintenance of electric potential favored retention of sodium in the plasma. Secondly, the osmotic gradient from dialysate to plasma is greatest at the start of dialysis, when plasma osmolality contains retained osmoles such as urea. This favors water movement from dialysate to plasma; when dialysate osmolality is reduced by using a lower dialysate sodium concentration, this effect is accentuated and increased water movement occurs from dialysate to plasma. This effect has been previously described [36-38].

While Pre- $\mathrm{N}+$ is stable as a "set point" in thrice weekly conventional hemodialysis patients [20-22], this has not been prospectively evaluated in quotidian or nocturnal home hemodialysis patients. A retrospective study by our research group found that conversion from thrice weekly conventional to quotidian hemodialysis associated with a reduction in SP, when $\mathrm{DPNa}^{+}$was neutral or negative [39]. We confirm a change in SP prospectively in this study, as mean pre- $\mathrm{Na}^{+}(137.4 \mathrm{vs}$. $136.8 \mathrm{mmol} / \mathrm{L}, \mathrm{p}=0.03)$ and slope of pre- $\mathrm{Na}^{+}(0.014 \mathrm{vs} .-0.015 \mathrm{mmol} / \mathrm{L} /$ day, $p=0.009$ ) (Table 2) differ between HIGHDialSOD and LOWDialSOD study periods. While the magnitude of the change in pre- $\mathrm{Na}^{+}$is small, this is both statistically and clinically important. Firstly, decreases in sodium setpoint are independently associated with increased mortality $[40,41]$. Secondly, hemodialysis units that use facility wide dialysate sodium prescriptions will lead many patients to having highly negative $\mathrm{DPNa}^{+}$and thus more exaggerated decreases in SP. Thirdly, in units that personalize dialysate sodium by following Pre$\mathrm{Na}^{+}$, repeated decreases in Dial- $\mathrm{Na}^{+}$to maintain a negative $\mathrm{DPNa}^{+}$ could cause repeated and undesirable decreases in SP. Finally, this raises the possibility that hemodialysis prescription might be modified to increase SP in vulnerable patients. More research will be required to determine the pathophysiologic mechanism of a change in SP in these patients, and to determine the impact on cardiovascular outcomes.

There are limitations to this study. Firstly, we did not measure blood glucose, lipids or paraprotein levels, each of which can impact plasma sodium measurement [42-44]. However, use of a randomized crossover study design negated these effects, since each patient served as their own control, and since these factors were unlikely to change for any particular patient between study periods. Secondly, our study population was small. However, our patients are highly compliant, having participated in multiple previous research trials $[13,14]$. This enabled the recording of numerous pre- and post-dialysis sodium values from all patients on multiple hemodialysis modalities. We were thus able to report statistically and clinically significant outcomes.

\section{Conclusion}

In conventional, quotidian and nocturnal home hemodialysis patients, the personalization of $\mathrm{Dial}-\mathrm{Na}^{+}$to lower than the SP decreases plasma sodium throughout hemodialysis. Furthermore, Dial- $\mathrm{Na}^{+}$can modify the Pre- $\mathrm{Na}^{+}$"set point". Further research is needed to determine the effect on cardiovascular morbidity and mortality.

\section{Acknowledgements}

This work was funded in part from a grant from the Program of Experimental Medicine at Western University. Salary support for author BT was provided by the Clinical Investigator Program at Western University.

\section{References}

1. United States Renal Data System (2013) USRDS 2013 Annual data report: Atlas of chronic kidney disease and end-stage renal disease in the united states. national institutes of health. National Institute of Diabetes and Digestive and Kidney Diseases. Bethesda, Maryland.

2. Allen RP, Picchietti D, Hening WA, Trenkwalder C, Walters AS, et al. (2003) Restless legs syndrome: Diagnostic criteria, special considerations, and epidemiology. A report from the restless legs syndrome diagnosis and epidemiology workshop at the National Institutes of Health. Sleep Med 4: 101-119.

3. Paoletti E, Specchia C, Di Maio G, Bellino D, Damasio B, et al. (2004) The worsening of left ventricular hypertrophy is the strongest predictor of sudden cardiac death in haemodialysis patients: A 10 year survey. Nephrol Dial Transplant 19: 1829-1834.

4. Kalantar-Zadeh K, Regidor DL, Kovesdy CP, Van Wyck D, Bunnapradist $S$, et al. (2009) Fluid retention is associated with cardiovascular mortality in patients undergoing long-term hemodialysis. Circulation 119: 671-679.

5. Kimmel PL, Varela MP, Peterson RA, Weihs KL, Simmens SJ, et al. (2000) Interdialytic weight gain and survival in hemodialysis patients: Effects of duration of ESRD and diabetes mellitus. Kidney Int 57: 1141-1151.

6. London GM, Pannier B, Guerin AP, Blacher J, Marchais SJ, et al. (2001) Alterations of left ventricular hypertrophy in and survival of patients receiving hemodialysis: Follow-up of an interventional study. J Am Soc Nephrol 12: 2759-2767.

7. Kayikcioglu M, Tumuklu M, Ozkahya M, Ozdogan O, Asci G, et al. (2009) The benefit of salt restriction in the treatment of end-stage renal disease by haemodialysis. Nephrol Dial Transplant 24: 956-962.

8. Ozkahya M, Ok E, Cirit M, Aydin S, Akçiçek F, et al. (1998) Regression of left ventricular hypertrophy in haemodialysis patients by ultrafiltration and reduced salt intake without antihypertensive drugs. Nephrol Dial Transplant 13: 1489-1493.

9. Chan CT, Greene T, Chertow GM, Kliger AS, Stokes JB, et al. (2012) Determinants of left ventricular mass in patients on hemodialysis: Frequent hemodialysis network (FHN) trials. Circ Cardiovasc Imaging 5: 251-261.

10. Culleton BF, Walsh M, Klarenbach SW, Mortis G, Scott-Douglas N, et al. (2007) Effect of frequent nocturnal hemodialysis vs conventional hemodialysis on left ventricular mass and quality of life: A randomized controlled trial. JAMA 298: 1291-1299. 
Citation: Thomson B, Li L, Lindsay R (2017) Effect of Personalized Dialysate Sodium Prescription on Plasma Sodium Concentration and Sodium Set Point in Conventional, Quotidian and Nocturnal Home Hemodialysis. J Nephrol Ther 7: 294. doi:10.4172/2161-0959.1000294

Page 6 of 6

11. Johansen KL, Zhang R, Huang Y, Chen SC, Blagg CR, et al. (2009) Survival and hospitalization among patients using nocturnal and short daily compared to conventional hemodialysis: A USRDS study. Kidney Int 76: 984-990.

12. Lacson E, Xu J, Suri RS, Nesrallah G, Lindsay R, et al. (2012) Survival with three-times weekly in-center nocturnal versus conventional hemodialysis. J Am Soc Nephrol 23: 687-695.

13. Lindsay RM (2004) The London, Ontario, daily/nocturnal hemodialysis study. Semin Dial 17: 85-91.

14. Rocco MV, Lockridge RS, Beck GJ, Eggers PW, Gassman JJ, et al. (2011) The effects of frequent nocturnal home hemodialysis: The frequent hemodialysis network nocturnal trial. Kidney Int 80: 1080-1091.

15. Hur E, Usta M, Toz H, Asci G, Wabel P, et al. (2013) Effect of fluid management guided by bioimpedance spectroscopy on cardiovascular parameters in hemodialysis patients: A randomized controlled trial. Am J Kidney Dis 61: 957-965.

16. Moissl U, Arias-Guillen M, Wabel P, Fontsere N, Carrera M, et al. (2013) Bioimpedance-guided fluid management in hemodialysis patients. Clin J Am Soc Nephrol 8: 1575-1582.

17. de Paula FM, Peixoto AJ, Pinto LV, Dorigo D, Patricio PJ, et al. (2004) Clinical consequences of an individualized dialysate sodium prescription in hemodialysis patients. Kidney Int 66: 1232-1238.

18. Hecking M, Karaboyas A, Saran R, Sen A, Inaba M, et al. (2012) Dialysate sodium concentration and the association with interdialytic weight gain, hospitalization, and mortality. Clin J Am Soc Nephrol 7: 92-100.

19. Sayarlioglu H, Erkoc R, Tuncer M, Soyoral Y, Esen R, et al. (2007) Effects of low sodium dialysate in chronic hemodialysis patients: An echocardiographic study. Ren Fail 29: 143-146.

20. Basile C, Libutti P, Lisi P, Vernaglione L, Casucci F, et al. (2013) Sodium setpoint and gradient in bicarbonate hemodialysis. J Nephrol 26: 1136-1142.

21. Keen ML, Gotch FA (2007) The association of the sodium "set point" to interdialytic weight gain and blood pressure in hemodialysis patients. Int J Artif Organs 30: 971-979.

22. Peixoto AJ, Gowda N, Parikh CR, Santos SF (2010) Long-term stability of serum sodium in hemodialysis patients. Blood Purif 29: 264-267.

23. Lambie SH, Taal MW, Fluck RJ, McIntyre CW (2005) Online conductivity monitoring: Validation and usefulness in a clinical trial of reduced dialysate conductivity. Asaio J 51: 70-76.

24. Thein H, Haloob I, Marshall MR (2007) Associations of a facility level decrease in dialysate sodium concentration with blood pressure and interdialytic weight gain. Nephrol Dial Transplant 22: 2630-2639.

25. Hecking M, Kainz A, Horl WH, Herkner H, Sunder-Plassmann G (2011) Sodium set point and sodium gradient: Influence on plasma sodium change and weight gain. Am J Nephrol 33: 39-48.

26. Foley RN, Herzog CA, Collins AJ (2002) Blood pressure and long-term mortality in United States hemodialysis patients: USRDS Waves 3 and 4 Study. Kidney Int 62: 1784-1790.

27. Hecking M, Karaboyas A, Saran R, Sen A, Horl WH, et al. (2012) Predialysis serum sodium level, dialysate sodium, and mortality in maintenance hemodialysis patients: The dialysis outcomes and practice patterns study (DOPPS). Am J Kidney Dis 59: 238-248.

28. Suckling RJ, Swift PA, He FJ, Markandu ND, MacGregor GA (2013) Altering plasma sodium concentration rapidly changes blood pressure during haemodialysis. Nephrol Dial Transplant 28: 2181-2186.

29. Shoji T, Tsubakihara Y, Fujii M, Imai E (2004) Hemodialysis-associated hypotension as an independent risk factor for two-year mortality in hemodialysis patients. Kidney Int 66: 1212-1220.

30. Locatelli F, Di Filippo S, Manzoni C (2000) Relevance of the conductivity kinetic model in the control of sodium pool. Kidney Int Suppl 76: S89-95.

31. Levey AS, Bosch JP, Lewis JB, Greene T, Rogers N, et al. (1999) A more accurate method to estimate glomerular filtration rate from serum creatinine: A new prediction equation. Modification of diet in renal disease study group. Ann Intern Med 130: 461-470.

32. Santos SF, Peixoto AJ (2008) Revisiting the dialysate sodium prescription as a tool for better blood pressure and interdialytic weight gain management in hemodialysis patients. Clin J Am Soc Nephrol 3: 522-530.

33. Flanigan MJ (1998) Sodium flux and dialysate sodium in hemodialysis. Semin Dial 11: 298-304.

34. Locatelli F, Di Filippo S, Manzoni C (1999) Sodium kinetics during dialysis. Semin Dial 12: S41-S44.

35. Moret K, Hassell D, Kooman JP, van der Sande F, Gerlag PG, et al. (2002) Ionic mass balance and blood volume preservation during a high, standard, and individualized dialysate sodium concentration. Nephrol Dial Transplant 17: 1463-1469.

36. Rodrigo F, Shideman J, McHugh R, Buselmeier T, Kjellstrand C (1977) Osmolality changes during hemodialysis: Natural history, clinical correlations and influence of dialysate glucose and intravenous mannitol. Ann Intern Med 86: 554-561.

37. Lopot F, Bláha J, Válek A (1992) An equation for calculating postdialysis plasma sodium. Int J Artif Organs 15: 354-357.

38. Swartz RD, Somermeyer MG, Hsu CH (1982) Preservation of plasma volume during hemodialysis depends on dialysate osmolality. Am J Nephrol 2: 189-194.

39. Thomson BK, Huang SH, Chan CT, House AA, Lindsay RM (2013) Plasma sodium setpoint: Is it constant or changed by hemodialysis prescription? Asaio J 59: 497-504.

40. Mc Causland FR, Waikar SS, Brunelli SM (2012) Increased dietary sodium is independently associated with greater mortality among prevalent hemodialysis patients. Kidney Int 82: 204-211.

41. Thijssen S, Usvyat L, Kotanko P (2012) Prediction of mortality in the first two years of hemodialysis: Results from a validation study. Blood Purif 33: 165-170.

42. Katz MA (1973) Hyperglycemia-induced hyponatremia--calculation of expected serum sodium depression. N Engl J Med 289: 843-844.

43. Ionescu-Tirgoviste C, Cheta D (1980) Misleading hyponatraemia in hyperlipaemic states. Lancet 1: 212 .

44. Weisberg LS (1989) Pseudohyponatremia: A reappraisal. Am J Med 86: 315-318. 